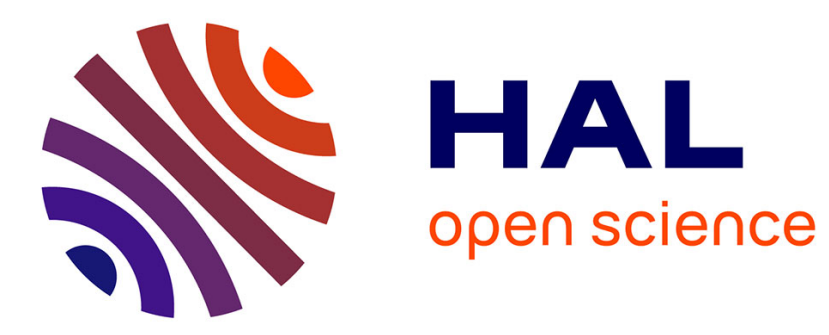

\title{
Simple method of determining the birefringence of nematic liquid crystals
}

\author{
F. Leenhouts, F. van Der Woude
}

\section{To cite this version:}

F. Leenhouts, F. van Der Woude. Simple method of determining the birefringence of nematic liquid crystals. Journal de Physique Lettres, 1978, 39 (14), pp.249-251. 10.1051/jphyslet:019780039014024900 . jpa-00231490

\section{HAL Id: jpa-00231490 https://hal.science/jpa-00231490}

Submitted on 1 Jan 1978

HAL is a multi-disciplinary open access archive for the deposit and dissemination of scientific research documents, whether they are published or not. The documents may come from teaching and research institutions in France or abroad, or from public or private research centers.
L'archive ouverte pluridisciplinaire HAL, est destinée au dépôt et à la diffusion de documents scientifiques de niveau recherche, publiés ou non, émanant des établissements d'enseignement et de recherche français ou étrangers, des laboratoires publics ou privés. 


\title{
SIMPLE METHOD OF DETERMINING THE BIREFRINGENCE OF NEMATIC LIQUID CRYSTALS
}

\author{
F. LEENHOUTS and F. VAN DER WOUDE
}

Solid State Physics Laboratory, Materials Science Center, University of Groningen, Groningen, The Netherlands

(Reçu le 27 avril 1978, accepté le 29 mai 1978)

\begin{abstract}
Résumé. - Une méthode simple pour déterminer la biréfringence des cristaux liquides nématiques est présentée. Cette méthode est basée sur une combinaison de deux techniques optiques. Pour la phase nématique de MBBA nous avons obtenu des résultats précis.
\end{abstract}

Abstract. - In this paper we describe a simple method of determining the birefringence of nematic liquid crystals. The method is based on a combination of two optical techniques. For the nematic liquid crystal MBBA, we have obtained reproducible and accurate results.

1. Introduction. - In the nematic liquid crystalline phase the long molecular axes tend to align along a preferred direction, the director $\mathbf{n}$. As a consequence the medium is birefringent; the ordinary refractive index $n_{0}$ is smaller than the extraordinary refractive index $n_{\mathrm{e}}$.

In several formulas of physical properties of nematic liquid crystals the birefringence $\Delta n=n_{\mathrm{e}}-n_{0}$ is an important parameter. Here we present a new method of determining the birefringence which actually combines two well known optical techniques and which gives accurate and reproducible results. The plan of the paper is as follows. First we will present in the next section the necessary formulas associated with one technique. In addition we will discuss the assumptions, which have been made by several authors concerning the wavelength dependence of $\Delta n$ in order to calculate $\Delta n$ using this technique. In section 3 we describe our method and compare our results for MBBA with $\Delta n$-values, obtained from a different technique.

2. Birefringence. - It is well known 11$]$ that the intensity of light traversing a planar oriental nematic crystal, placed between a polarizer and an analyser, depends on the wavelength. If the polarizer and the analyser are parallel and at an angle of $\pi / 4$ with respect to the director $\mathbf{n}$, the intensity of the transmitted light is given by :

where

$$
\begin{aligned}
& I=I_{0}\left(1-\sin ^{2}(\delta / 2)\right) \\
& \delta=2 \pi d\left(n_{e}-n_{0}\right) / \lambda .
\end{aligned}
$$

Here $I$ is the intensity of the transmitted light, $d$ is the thickness of the empty cell, $\lambda$ the wavelength of the light and $\Delta n=n_{\mathrm{e}}-n_{0}$ the birefringence. If the wavelength is changed continuously, for instance by using a spectrophotometer, the transmitted light will show maxima and minima. A typical recording of the spectrophotometer is shown in figure 1 . The intensity will show maxima and minima if the following condition is fulfilled :

$$
2 \pi d\left(n_{\mathrm{e}}-n_{0}\right) / \lambda_{i}=\left(k_{1}+i-1\right) \pi .
$$

In this expression $k_{1}$ is the order of the first extremum at the long wavelength side of the spectrophotometer spectrum and $k_{i}=\left(k_{1}+i-1\right)$ is the order of the $i$-th extremum with wavelength $\lambda_{i}$. For a maximum $k_{1}+i-1$ is even and for a minimum $k_{1}+i-1$ is odd.

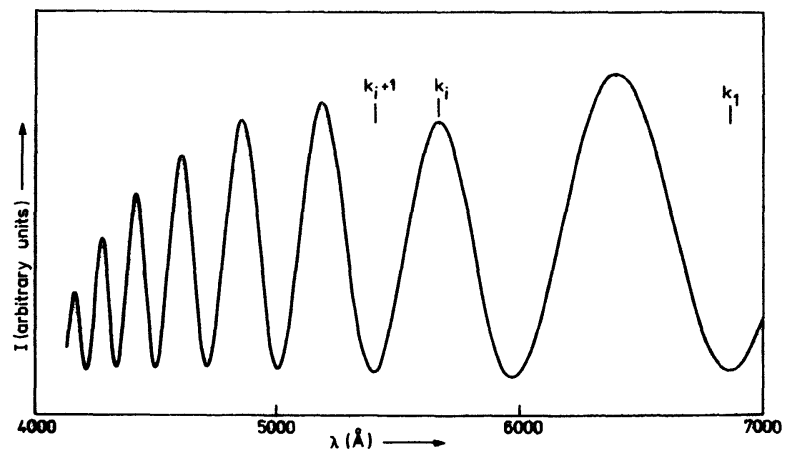

Fig. 1. - Spectrum of a planar oriented nematic placed between a polarizer and an analyser. The polarizer and analyser are parallel and at an angle of $\pi / 4$ with respect to the director. The order of the extrema is denoted by the factors $k_{i}$. 
Equation (2) shows that the factor $k_{1}$ has to be known in order to calculate the birefringence from the spectrum. Without knowing this factor, several authors have made assumptions concerning the wavelength dependence of the birefringence in order to calculate $\Delta n$ from equation (2). In his earlier communications $[1,2]$ Chang made the approximation

$$
\Delta n_{i}=\Delta n_{i+1}
$$

where $\Delta n_{i}$ and $\Delta n_{i+1}$ are the values of the birefringence at two consecutive maxima (or minima) $\lambda_{i}$ and $\lambda_{i+1}$ respectively. However as Chang has pointed out subsequently [3], this approximation will lead to substantial differences in practice and overestimates the birefringence values by about 20 to 30 percent in the red region and an even higher percentage at shorter wavelengths.

In order to account for the wavelength dependence of the birefringence Laurent and Journeaux [4] made the approximation for the birefringence in the red region :

$$
\begin{aligned}
& \Delta n_{i+1}=\Delta n_{i}+\varepsilon \\
& \Delta n_{i+2}=\Delta n_{i+1}+\varepsilon .
\end{aligned}
$$

Here $\Delta n_{i}, \Delta n_{i+1}$ and $\Delta n_{i+2}$ are the values of the birefringence at three consecutive maxima (or minima) $\lambda_{i}, \lambda_{i+1}$ and $\lambda_{i+2}$ where $\lambda_{i+2}<\lambda_{i+1}<\lambda_{i}$. Using equations (2) and (3) the following equations can be derived :

$$
\begin{aligned}
\Delta n_{i} & =\left(\lambda_{i} /\left(\lambda_{i}-\lambda_{i+1}\right)\right)\left(\lambda_{i+1} / d-\varepsilon\right) \\
\Delta n_{i+1} & =\left(\lambda_{i+1} /\left(\lambda_{i+1}-\lambda_{i+2}\right)\right)\left(\lambda_{i+2} / d-\varepsilon\right) .
\end{aligned}
$$

Using equations (3) and (4), $\varepsilon$ and $\Delta n$ can be calculated. However we have found that the value of $\varepsilon$, calculated in this way, is very sensitive to small uncertainties in the wavelengths $\lambda_{i}$ of the extrema. As a consequence this approximation may also lead to considerable errors in practice.

As we have pointed out already, the birefringence values could be derived accurately from the spectrum if the factor $k_{1}$ and the thickness $d$ were known.

3. Description of the method and results. - First we have measured the ordinary refractive index $n_{0}$ in the nematic phase and the refractive index $n$ in the isotropic phase with an Abbe-refractometer for the yellow sodium line $(5893 \AA)$. It is well known that the functioning of this instrument is based on internal reflection of light at the interface between the liquid and the surface of an optically dense prism. The maximum measurable index of refraction is therefore that of the glass which in general is lower than $n_{\mathrm{e}}$. The result of the measurements for MBBA is shown in figure 2. As estimate of $\bar{n}=\left(2 n_{0}+n_{\mathrm{e}}\right) / 3$ in the nematic phase can be found by merely extrapolating linearly the refractive index from the isotropic to the

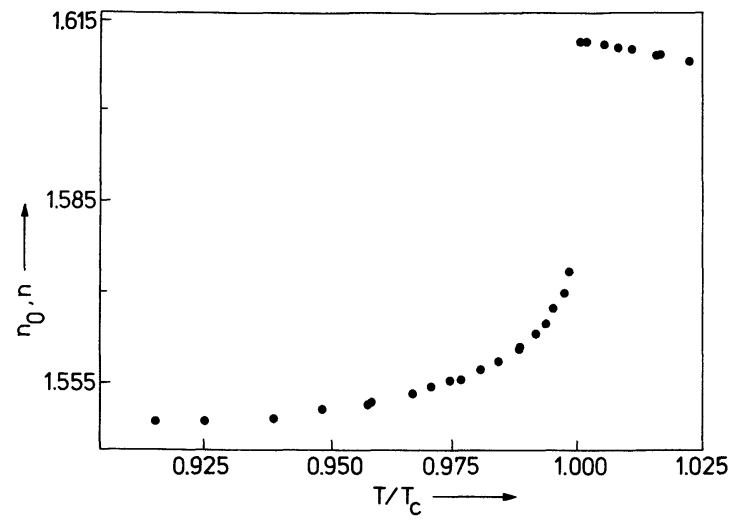

Fig. 2. - Temperature dependence of the refractive index $n_{0}$ in the nematic phase and the refractive index $n$ in the isotropic phase as measured with an Abbe refractometer for MBBA at $5893 \AA$.

nematic phase. In this way a rough estimate of $\Delta n$ for any particular temperature can be found. Let us call this estimate $\Delta n^{\mathrm{e}}$. However the values of $\bar{n}$ in the nematic phase, obtained from the extrapolation procedure, will be different from the true values, since the density shows a finite jump (some tenths of a percent) at the clearing point and since the density is more temperature dependent in the nematic than in the isotropic phase. Consequently the values of $\Delta n^{\mathrm{e}}$ calculated in this way may differ from the true values. However as De Jeu [5] has pointed out the quantity $\overline{n^{2}} / \rho$, where $\overline{n^{2}}=\left(2 n_{0}^{2}+n_{\mathrm{e}}^{2}\right) / 3$ and $\rho$ is the density, is about equal in the nematic and the isotropic phase. Since $\overline{n^{2}} \simeq \bar{n}^{2}$ and the temperature dependence of $\rho$ is small we can expect that the extrapolated values $\bar{n}$ will not differ much from the true values. This conclusion can be tested by using Haller's data for-a comparison of $\Delta n^{\mathrm{e}}$ and the true values. Haller et al. [6] have measured directly both $n_{0}$ and $\Delta n$ in the nematic phase and the refractive index $n$ in the isotropic phase for several materials. The ordinary refractive index $n_{0}$ and the refractive index $n$ in the isotropic phase have been measured with an Abbe-refractometer and the birefringence has been obtained by measuring the spacings of extinction bands of wedge shaped samples. Using these data we found that the estimated values differ from the true values by less than ten percent, which is accurate enough for our analysis as will be shown in the next paragraph.

Now we come to the calculation of the factor $k_{1}+i-1$ in equation (2). We substitute the value of $\Delta n^{\mathrm{e}}$, obtained from the extrapolation procedure in equation (2), where $\lambda_{i}$ now is the wavelength of the extremum closest to the yellow sodium line (5 $893 \AA$ ). If the thickness $d$ is known the factor $k_{i}=k_{1}+i-1$ can be calculated. Of course $k_{i}$ will not be an integer in general. Let us call the value of $k_{i}$ calculated in this way $k_{i}^{\mathrm{e}}$. The true value $k_{i}$ can be found by merely rounding off the calculated value of $k_{i}^{\mathrm{e}}$ upwards or downwards to an odd or even integer. In this respect it should be noted that the requirement must be 
fulfilled that $k_{i}$ is even if the extremum $\lambda_{i}$ is a maximum, and odd if it is a minimum. Knowing $k_{i}$ the birefringence values for all extrema of the spectrum can be calculated. In table I we have presented the results of a calculation for a sample with a thickness of about $9 \mu$. The columns one, two and three list the reduced temperature, the estimated value $\Delta n^{\mathrm{e}}$ obtained from the extrapolation procedure and the wavelength of the extremum closest to the $5893 \AA$-line respectively, which is a maximum or a minimum (column four). Finally in columns five and six the values $k_{i}^{\mathrm{e}}$ and $k_{i}$ are given. Consider for instance the first row of the table. We have calculated $k_{i}^{\mathrm{e}}$ to be 3.40 for the extremum closest to the $5893 \AA$-line. Since the extremum is a maximum, $k_{i}$ has to be 4 . The second best choices for $k_{i}$, namely $k_{i}$ equals 2 , or $k_{i}$ equals 6 , would lead to values of the birefringence, which are about forty percent lower or sixty percent higher respectively than the estimated value. However this cannot be reconciled with the small discontinuity of the density at the clearing point and the small difference in the temperature dependence of the density between the nematic and the isotropic phase. It should be mentioned that only for small values of $k$ can a unique choice for $k$ be made. So the whole procedure mentioned above is only trustworthy if thin samples are used. In practice we use sample cells with thicknesses varying from about 10 to $25 \mu$.

\section{TABLE I}

Factors $k_{i}$ calculated from $\Delta n^{\mathrm{e}}$ for a $9 \mu \mathrm{m}$ thick sample

$\begin{array}{cccccr}T / T_{\mathrm{c}} & \Delta n^{\mathrm{e}} & \lambda_{i}(\AA) & \max / \min & k_{i}^{\mathrm{e}} & k_{i} \\ - & - & - & - & - & - \\ 0.9980 & 0.1163 & 5806 & \max & 3.40 & 4 \\ 0.9900 & 0.1525 & 5593 & \min & 4.73 & 5 \\ 0.9827 & 0.1677 & 5894 & \min & 4.78 & 5 \\ 0.9604 & 0.1952 & 5747 & \max & 5.77 & 6\end{array}$

The thickness of the empty sample cells is measured interferometrically [7] with an accuracy of about 0.5 percent. The measurements of the birefringence have been performed using a Beckman DK-2 A double beam spectrophotometer. In order to do measurements as a function of temperature we have built an oven, which can be inserted in the sample compartment of the spectrophotometer. The temperature of the oven is kept constant (within $0.1^{\circ} \mathrm{C}$ ) by means of a current stabilizing DC-supply.

Finally we present in table II the results of our measurements on three samples with different thicknesses for the nematic liquid crystal N-(p-methoxybenzylidene)-p-butylaniline (MBBA). The clearing point of the MBBA was $46.2^{\circ} \mathrm{C}$. During the measurements the MBBA hardly deteriorated, since the sample cells were prepared carefully and since the MBBA was not in contact with air [7]. The clearing point dropped less than $0.1^{\circ} \mathrm{C}$. The results of the
TABLE II

Birefringence $\Delta n v s$. reduced temperature $T / T_{\mathrm{c}}$ for MBBA at three wavelengths

\begin{tabular}{cccc}
$T / T_{\mathrm{c}}$ & \multicolumn{3}{c}{$\Delta n$} \\
\cline { 2 - 4 }- & $6328 \AA$ & $5893 \AA$ & $5461 \AA$ \\
0.9418 & $\overline{0.209}$ & 0.217 & 0.229 \\
0.9445 & 0.207 & 0.215 & 0.228 \\
0.9604 & 0.194 & 0.201 & 0.213 \\
0.9685 & 0.186 & 0.194 & 0.204 \\
0.9699 & 0.185 & 0.192 & 0.203 \\
0.9827 & 0.169 & 0.175 & 0.185 \\
0.9843 & 0.165 & 0.172 & 0.181 \\
0.9851 & 0.163 & 0.170 & 0.179 \\
0.9900 & 0.157 & 0.162 & 0.170 \\
0.9936 & 0.144 & 0.149 & 0.157 \\
0.9960 & 0.134 & 0.140 & 0.148 \\
0.9980 & 0.129 & 0.136 & 0.144
\end{tabular}

measurements are displayed in figure 3 together with the data of Haller et al. [8]. First we note that the reproducibility of our measurements is excellent and secondly we see that our data agree well with the data of Haller et al., who have obtained $\Delta n$ directly by measuring the spacings of extinction bands of wedge shaped samples. The accuracy of our measurements is estimated to be about 1 percent.

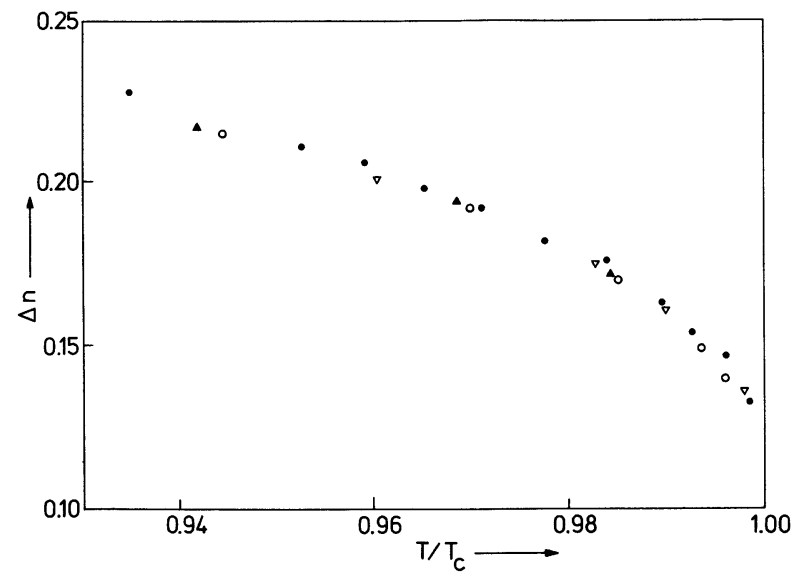

FIG. 3. - Birefringence $\Delta n$ of MBBA vs. reduced temperature at $5893 \AA$. The open circles and triangles represent our measurements on three samples with different thicknesses and the filled circles represent data from reference [8].

\section{References}

[1] Chang, R., Mater. Res. Bull. 7 (1972) 267.

[2] Chang, R., Mol. Cryst. Liq. Cryst. 28 (1974) 1.

[3] Chang, R., Mol. Cryst. Liq. Cryst. 34 (1976) 65.

[4] Laurent, M., Journeaux, R., Mol. Cryst. Liq. Cryst. 36 (1976) 171.

[5] De Jeu, W. H., Claasen, W. A. P., J. Chem. Phys. 68 (1978) 109.

[6] Haller, I., Huggins, H. A., Lilienthal, H. R., Mc Guire, T. R., J. Phys. Chem. 77 (1973) 950.

[7] Leenhouts, F., van der Woude, F., Dekker, A. J., Phys. Lett. 58A (1976) 242.

[8] Haller, I., Huggins, H. A., Freiser, M. J., Mol. Cryst. Liq. Cryst. 16 (1972) 53. 